Fanum

Sociológico

\section{Forum Sociológico}

Série II

$38 \mid 2021$

Número 38

\title{
Ressignificar para renovar : Novos usos, representações e resistências na Praça Sete, Belo Horizonte
}

Resignify to renew: New uses, representations and resistances in Praça Sete, Belo Horizonte

\section{Renata de Leorne Salles}

\section{(2) OpenEdition \\ Journals}

\section{Edição electrónica}

URL: https://journals.openedition.org/sociologico/9654

DOI: 10.4000/sociologico.9654

ISSN: 2182-7427

\section{Editora}

CICS.NOVA - Centro Interdisciplinar de Ciências Sociais da Universidade Nova de Lisboa

\section{Edição impressa \\ Paginação: 25-34 \\ ISSN: 0872-8380}

\section{Refêrencia eletrónica}

Renata de Leorne Salles, «Ressignificar para renovar : Novos usos, representações e resistências na Praça Sete, Belo Horizonte», Forum Sociológico [Online], 38 | 2021, posto online no dia 02 junho 2021, consultado o 30 março 2022. URL: http://journals.openedition.org/sociologico/9654 ; DOI: https:// doi.org/10.4000/sociologico.9654 


\title{
RESSIGNIFICAR PARA RENOVAR: NOVOS USOS, REPRESENTAÇÕES E RESISTÊNCIAS NA PRAÇA SETE, BELO HORIZONTE

\author{
RESIGNIFY TO RENEW: NEW USES, REPRESENTATIONS AND RESISTANCES \\ IN PRAÇA SETE, BELO HORIZONTE
}

DOI: https://doi.org/10.4000/sociologico.9654

Renata de Leorne Salles

Pontifícia Universidade Católica de Minas Gerais - PUC Minas, Programa de Pós-graduação em Ciências Sociais, Departamento de Ciências Sociais, Belo Horizonte, Brasil. ORCID: https://orcid.org/0000-0002-5722-3753

\begin{abstract}
Resumo
A partir das últimas décadas do século XX, quando a preservação do patrimônio cultural ganhava relevância no Brasil, novas políticas urbanas emergiram para recuperar centros históricos considerados degradados, atribuindo-Ihes funções atreladas à cultura. Logo, surgiram novos equipamentos culturais em localidades com potencial para atrair pessoas mais abastadas, conforme o poder público. Diante disso, pesquisou-se a revitalização do Cine Brasil, um antigo cinema de rua localizado na área central de Belo Horizonte, na Praça Sete, cuja consequente reabertura como espaço cultural, em 2013, foi uma experiência de renovação através da ressignificação do patrimônio. Levando em conta as representações capturadas em campo, obtidas através dos dados qualitativos provenientes de entrevistas semiestruturadas, foi possível averiguar os desdobramentos do novo equipamento, possibilitando elencar mudanças e permanências nas dinâmicas locais do espaço público renovado. Os resultados apontaram que a presença circunstancial de novos usuários consumidores de cultura não está sendo capaz de alterar os usos populares já consolidados na região.
\end{abstract}

Palavras-chaves: patrimônio cultural, áreas centrais, renovação urbana, representações

\begin{abstract}
From the last decades of the 20th century, when the preservation of cultural heritage gained relevance in Brazil, new urban policies emerged to recover historical centers considered degraded, assigning them functions linked to culture. Soon, new cultural equipment arose in locations with the potential to attract more affluent people, according to the government. So, we researched the revitalization of Cine Brasil, an old street cinema located in the central area of Belo Horizonte, in Praça Sete, whose consequent reopening as a cultural space in 2013 was an experience of renewal through the resignification of heritage. Taking into account the representations captured in the field, obtained through qualitative data from semi-structured interviews, it was possible to verify the effects of the new equipment, allowing to list changes and permanences in the local dynamics of the renovated public space. The results showed that the circumstantial presence of new users who consume culture is not being able to change the popular uses already consolidated in the region.
\end{abstract}

Keywords: culture, cultural heritage, central areas, urban renewal, representations

\section{Introdução}

Este artigo pretende demonstrar os desdobramentos socioespaciais da reabertura, em 2013, de um antigo cinema de rua conhecido popularmente como Cine Brasil, situado no centro tradicional de Belo Horizonte (Minas Gerais, Brasil), mais precisa- mente na região da Praça Sete, também conhecida como "coração da cidade" devido à sua centralidade e importância histórica. Com base na interpretação das narrativas obtidas dos novos usuários identificados em cena, tanto no novo espaço cultural (público frequentador) quanto no cotidiano do entorno revitalizado do prédio (vendedores ambulantes, 
comerciantes, transeuntes), buscou-se compreender os desdobramentos socioespaciais acarretados no espaço público da porção analisada, observando possíveis mudanças e/ou permanências nas práticas sociais advindas com o processo de patrimonialização do edifício histórico.

Outros casos empíricos em centros urbanos brasileiros, cujo apelo cultural do patrimônio também foi tido como o fio condutor dos processos de revitalização, serão igualmente apresentados para incrementar o debate sobre como tais políticas culturais vêm sendo (ou não) responsáveis pela constituição de novas práticas contemporâneas devido à probabilidade de atração de novos usuários mais abastados, conforme previsto pelo poder público. Em outras palavras, buscou-se identificar a existência de novas formas de ocupação nesses sítios urbanos renovados na tentativa de compreender como as representações que vêm sendo construídas pelos distintos grupos sociais se relacionam com as dinâmicas desenvolvidas no espaço público da atualidade.

A valorização do patrimônio (material e imaterial) promovida pela Unesco na década de 1970 emoldurou as discussões urbanísticas internacionais a partir de então, criando modelos de revitalização atrelados à cultura - que foram adotados na América Latina mais tarde - , gerando uma conscientização mundial em torno da manutenção de bens culturais, relevantes para a preservação da memória e história dos cidadãos. Com isso, tais propostas tornaram-se estratégias recorrentes para a (re)valorização de sítios urbanos.

Paralelamente, nos anos 1970 e 1980, o espaço urbanizado das cidades brasileiras se expandia cada vez mais rumo às periferias. A maioria das áreas centrais, à época, se encontravam fisicamente deterioradas, inseguras e estigmatizadas por parte da população, com edifícios abandonados devido à perda de moradores e de atividades relacionadas às camadas médias e altas, que migravam para novos bairros emergentes. Como consequência, o espaço público das ruas e calçadas foi sendo ocupado pelo comércio popular informal.

Logo, a retomada do olhar para as áreas centrais tornou-se pauta em diversas agendas urbanas, principalmente após a década de 1990, quando a preservação do patrimônio cultural adquiriu maior visibilidade no Brasil e fez surgir novas políticas públicas culturais para recuperar as referências simbólicas e afetivas da população no contexto da metrópole contemporânea. Tais políticas, voltadas para a retomada desses centros degradados, começaram a surgir através de práticas incorporadas a ações de intervenção mais abrangentes (Bidou-Zachariasen, 2006) visando a recuperação socioeconômica dessas localidades através da proposição de novos usos. Com isso, pessoas de maior poder aquisitivo seriam atraídas para fins de entretenimento e consumo cul- tural e, assim, o valor do patrimônio seria resgatado. Pressupunha-se, por parte do poder público, que a demanda advinda desses novos atores seria capaz de contribuir para a proliferação de novos serviços e negócios, colaborando para minimizar ou eliminar a representação social negativa que permeia, de modo geral, tais locais históricos. Com isso, o espaço público poderia ser (re)criado através da dimensão cultural, sendo capaz de promover a tão desejada diversidade social em prol do direito à cidade.

Para facilitar o debate acerca da questão proposta, este artigo foi estruturado em seis partes, além desta introdução. Na primeira apresenta-se a metodologia utilizada na pesquisa, seguida pela descrição de um panorama do planejamento urbano contemporâneo para entendermos, com mais detaIhes, como o patrimônio cultural se tornou estratégico nas políticas públicas das últimas décadas. A terceira parte contempla o nosso objeto de estudo com base em uma pesquisa de minha autoria finalizada em $2019^{1}$, cujo foco foi a reabertura do Cine Brasil. Na quarta parte, apresentaremos mais dois casos brasileiros que, apesar das distintas escalas espaciais (em comparação ao caso estruturante deste trabalho), possuem similaridades advindas da renovação do patrimônio. Em seguida falaremos sobre as representações sociais que vêm sendo construídas pelos distintos atores, relacionando as ressignificações acerca do patrimônio renovado que reverberam na apropriação do espaço público contemporâneo. Por fim, tecerei algumas considerações finais.

\section{Metodologia}

Os dados qualitativos apresentados neste artigo sobre o caso de Belo Horizonte provêm de observação participante realizada em novembro de 2018 e entre abril e junho de 2019. Realizaram-se visitas regulares à Praça Sete em diferentes períodos (manhã, tarde e noite), durante os dias úteis para investigar o cotidiano da região, e também aos finais de semana, quando a cena urbana se modifica e o acelerado ritmo do dia a dia é substituído por outras formas de apropriação do espaço, cuja ocupação é mais difusa e interligada às atividades de lazer de determinados grupos. As visitas tiveram, em média, duas a três horas de duração, nas quais foram feitos, além de notas escritas, registros fotográficos para ilustrar e documentar os dados da pesquisa.

Foram realizadas diversas conversas informais, na tentativa de capturar o contexto investigado; posteriormente, foram feitas 24 (vinte e quatro) entrevistas semiestruturadas para identificar as dinâmicas do espaço público renovado da Praça Sete e do Cine Brasil, em dias de evento. Também foram coletadas informações sobre escolaridade, ocupação e local de residência dos entrevistados, possibilitando traçar um perfil dessas pessoas, 
além de suas principais impressões sobre as revitalizações.

As pessoas entrevistadas foram escolhidas de maneira arbitrária e divididas em dois grupos: a) usuários locais (vendedores ambulantes, comerciantes, transeuntes); b) usuários/frequentadores do Cine Brasil. A escolha etnográfica com base nas falas dos atores que constituem a vida pública local foi feita na tentativa de apreender as representações que vêm se conformando na atualidade em torno do objeto de estudo. Dessa forma, através das narrativas obtidas, identificaram-se apreciações similares dentro de um mesmo grupo e divergentes entre eles, o que viabilizou a construção das percepções de cada grupo para além dos estigmas já conhecidos.

Os eventos culturais promovidos pela casa foram também contemplados, tanto através da agenda disponibilizada no site institucional do Cine Brasil quanto a partir do acompanhamento dos preços ofertados que, no geral, podem ser considerados altos, fato que evidencia o direcionamento do consumo cultural para um público pré-determinado, contrapondo a proposta presente no discurso institucional sobre a oferta de um local democrático, capaz de abarcar um público diversificado.

\section{Planejamento urbano contemporâneo: Revitalização de áreas centrais}

Para melhor compreendermos os processos de renovação ocorridos na Praça Sete nos anos 2000, discorreremos sobre o planejamento urbano contemporâneo num contexto mais amplo; procuraremos assim entender também como se iniciaram as intervenções em áreas urbanas centrais e a importância que o patrimônio cultural foi adquirindo no âmbito dessas novas políticas urbanas².

Devido ao acelerado processo de expansão das grandes cidades no século $X X$, o planejamento urbano moderno passou a ser alvo de críticas em decorrência dos problemas estimulados pela ordem capitalista e por modelos funcionalistas. O rápido crescimento das metrópoles promoveu mudanças, tanto no tecido urbano quanto nas estruturas de classe, deteriorando socioespacialmente muitas localidades como, por exemplo, algumas áreas centrais. As condições de mobilidade, os fatores de localização das habitações e das atividades, os hábitos de consumo e a capacidade do Estado de regular as dinâmicas socioterritoriais já não eram mais os mesmos da antiga cidade industrial.

Nos anos 1960, nos Estados Unidos e na Inglaterra, quando se iniciou o processo de (re)ocupação de centros urbanos pelos estratos médios e altos que promoveu a expulsão da população residente de menor renda, um novo fenômeno começou a ser observado denominado gentrificação ${ }^{3}$. Tal conceito foi se expandindo e logo passou a ser usado para qualificar intervenções em centros históricos que, em decorrência das novas funções que Ihes vão sendo atribuídas, começaram a atrair usuários de maior poder aquisitivo. Dessa maneira, a gentrificação passou a ser utilizada na tentativa de compreender o caráter dessas intervenções, como afirmam Leite (2006) e Frúgoli Jr. (2000).

Após a década de 1970, o caráter mais pontual das propostas se interligou aos processos de desindustrialização das cidades, que foram se convertendo em centros financeiros e de entretenimento, do ponto de vista turístico e comercial (Frúgoli Jr., 2000). A suburbanização, ou seja, a expansão dos subúrbios de classe média no contexto do pós-guerra, assim como o surgimento dos shopping centers nas décadas de 1960 e 1970 - cenário típico dos Estados Unidos - contribuíram fortemente para o declínio dos centros urbanos comerciais tradicionais.

Diante disso, as zonas urbanas centrais, ademais das antigas zonas industriais e/ou portuárias, se converteram no principal foco das políticas urbanas internacionais e, mais tarde, nacionais, e passaram a contar com os setores privados a fim de recuperar e investir nesses territórios relativamente esvaziados e/ou abandonados visando uma maior rentabilidade (Compans, 2004). Primeiramente, o mercado imobiliário começou a conduzir tais ações, que logo foram convertidas em estratégias para a proposição de políticas públicas. Assim, com os aportes da iniciativa privada, práticas de consumo foram incorporadas ao discurso. Além disso, foram consideradas as questões relacionadas ao patrimônio construído e à identidade cultural local para reinventar a paisagem urbana. Ademais da preocupação estética, havia também o interesse em resgatar a interação social propiciada pelo espaço público (Corte-Real, 2015).

A partir dos anos 1980, os temas envolvendo as políticas urbanas ganharam relevância, e uma série de novas propostas e abordagens ligadas ao planejamento urbano contemporâneo surgiu para adequar as novas necessidades da sociedade às estruturas urbanas da cidade pós-industrial, estas empenhadas em redefinir os espaços minimizando os problemas de exclusão social e explosões demográfica e espacial advindas da urbanização, aliadas à reativação econômica de regiões obsoletas.

Assim, os investimentos do setor privado em políticas públicas foram se tornando recorrentes em algumas cidades brasileiras, muitas vezes ancorados em projetos com forte apelo visual e de marketing (Sant'Anna, 2010) visando a renovação urbana para atrair um novo público consumidor de cultura e/ou voltado para grandes eventos e negócios. Em pouco tempo, os aportes privados se convertem em estratégia geral do planejamento urbano para garantir a promoção da cidade ou a atratividade de determinados espaços. Com as denominadas 
parcerias público-privadas, começaram a proliferar, em termos mundiais, intervenções higienistas e artificializadas, mesmo frente à difusão de discursos para a retomada do espaço público heterogêneo (Jayme \& Trevisan, 2012) ${ }^{4}$.

Nesse sentido, valorizar a paisagem urbana, estética e simbolicamente, tornou-se essencial no contexto de reconstrução do patrimônio, que é, dessa maneira, reapropriado para fins mercadológicos, enquanto seus usos são direcionados para as camadas médias e altas da população. No geral, parte-se do pressuposto de que o poder público não teria os recursos necessários para subsidiar revitalizações capazes de reverter quadros de degradação socioespacial e econômica (Corte-Real, 2015), fato que corrobora a transformação do patrimônio em mercadoria cultural para o lazer, o consumo e o turismo de uma parcela da população.

São desse período, no Brasil, as intervenções das cidades turísticas de Recife (Bairro do Recife Antigo), Salvador (Centro Histórico, sobretudo o Pelourinho) e Rio de Janeiro (Rio Cidade), que almejavam certa animação cultural em centros históricos para o alcance dos efeitos desejados. Porém, o incremento do lazer e do consumo cultural direcionado para as camadas abastadas evidenciou problemas sociais relacionados às exclusões promovidas com a chegada desses novos usuários em territórios demarcados, predominantemente, pela classe popular.

Principalmente após os anos 2000, a cultura, além de impactar significativamente no desenvolvimento econômico de vários pontos da cidade, adquiriu um novo significado, se tornando recurso fundamental para a transformação do espaço urbano contemporâneo. Assim, a relação entre revitalização e políticas culturais passou a ser retratada como medidas unificadas, seja para alavancar socioeconomicamente determinados locais a partir de aportes da iniciativa privada, seja para viabilizar a preservação do patrimônio através de novos usos. Com isso, efeitos multiplicadores são previstos pelo poder público, ou seja, mais investimentos privados e, logo, mais negócios, serviços e pessoas circulando em áreas centrais renovadas, como pretendeu-se nas intervenções de Belo Horizonte (Praça Sete) e São Paulo (Bairro da Luz) a partir da implementação de novos equipamentos culturais. Mas será que isso é o que, de fato, vem ocorrendo?

Em termos gerais, como consequência desses modelos de revitalização, nota-se a degradação - devido à não apropriação do espaço - ou a (re) apropriação dessas regiões por usuários de maior poder aquisitivo a partir de ações que refletem os interesses do capitalismo globalizado. Incorporando modelos empresariais na gestão urbana em prol da competitividade e do crescimento econômico com base nas novas demandas mercadológicas (valori- zação imobiliária, segurança etc.), esses locais se transformaram em espaços modernos, atrativos e rentáveis. A recorrência de tais ações, que muitas vezes provocam uma expropriação urbana, pode ser exemplificada pelos grandes projetos de revitalização, pelas privatizações dos espaços públicos, pelas operações urbanas consorciadas ou pela promoção dos chamados "megaeventos", causando grandes modificações na estrutura socioespacial das metrópoles contemporâneas ${ }^{5}$. A valorização simbólica e estética da paisagem urbana como foco da narrativa de reconstrução do patrimônio o converte, dessa forma, em mercadoria para o consumo turístico e cultural. Dessa maneira, tanto os usos quanto os usuários se modificam, podendo acarretar novas formas de exclusão em concomitância ao surgimento de outras apropriações espaciais, muitas vezes resultando em diversos conflitos e disputas territoriais.

No caso de Belo Horizonte, cuja reinauguração do Cine Brasil foi uma estratégia corroborativa para (re)valorizar a Praça Sete através do resgate do valor simbólico do edifício, os processos de renovação da área central parecem não se enquadrar no cenário mencionado, talvez por se tratar de uma cidade que já nasceu moderna, e cujo centro não passou por processos de degradação similares aos centros históricos de cidades brasileiras mais antigas ${ }^{6}$. Além disso, a capital mineira não é uma cidade global, nem possui forte apelo turístico. Desse modo, buscaremos compreender as permanências identificadas sob a ótica etnográfica, a partir das representações construídas pelos atores locais contemporâneos, já que não foram comprovadas mudanças significativas na composição social da região, como era previsto pelo poder público. As práticas cotidianas populares seguiram da mesma maneira, apesar da presença circunstancial de novos atores na localidade.

\section{Belo Horizonte: O Cine Brasil e a revitalização da Praça Sete}

No centro tradicional da capital mineira, desde a década de 1980, encontramos diversas proposições nos moldes do planejamento urbano contemporâneo visando a recuperação socioeconômica local. Mas foi somente nos anos 2000 que muitas propostas até então não executadas foram retomadas e realizadas pelo poder público. Dentre elas, iniciada em 2003, temos a revitalização da região da Praça Sete, importante centralidade metropolitana e de imensa vitalidade que se situa no cruzamento de quatro vias importantes para a mobilidade urbana. Em uma das esquinas se encontra o edifício do Cine Brasil, principal referência arquitetônica local. Além disso, o obelisco que demarca o centro da Praça, conhecido carinhosamente pelos moradores como "Pirulito da Praça Sete", constitui um marco histórico, simbólico e afetivo para muitos belo-horizontinos. 
Ademais desta intervenção, entre os anos de 2005 e 2006, houve a ampliação dos locais de descanso, encontro e lazer da localidade com a repaginação dos quatro quarteirões que circundam a Praça e que possuem uso exclusivo peatonal desde a década de 1970; constituem desde então áreas notáveis de permanência, propiciando o convívio entre os mais distintos grupos sociais.

em seu fechamento em 1999. O prédio manteve-se em estado de abandono até a viabilização de sua compra, em 2006, por uma nova empresa privada, com a mediação do poder público, visando seu restauro e reabertura para impulsionar a renovação da área central que, à época, já era palco de diversas ações de requalificação. A cultura foi tida como um dos eixos estruturadores e, logo, as políticas de preservação do patrimônio, na tentativa de valorizar o passado a partir da manutenção dos espaços coletivos e dos edifícios históricos (Moreira, 2009).

Em 2013, o equipamento cultural foi reinaugurado e um novo uso Ihe foi atribuído ${ }^{7}$, consistindo em uma estratégia para recuperar seu valor simbólico e, dessa maneira, fomentar a apropriação do espaço público com a promoção de novas práticas sociais (Jayme \& Trevisan, 2012). O poder público acreditava que a transformação da realidade socioeconômica do centro ocorreria com a diversificação das atividades locais e a inclusão social nos espaços de uso coletivo.

Dessa forma, para verificar o que se passa na região atualmente, buscou-se apreender as opiniões

O antigo cinema de rua, datado de 1932, se consolidou como um importante local de encontro das classes média e alta da cidade desde seus primeiros anos, assim como o próprio centro tradicional, cujas sociabilidades que ali se manifestaram estavam interligadas a diversos locais de lazer como cinemas de rua, teatros e cafés, que configuravam a paisagem urbana (Lemos, 2010), refletindo a modernidade em voga e deixando para trás o provincianismo associado ao campo. Desse modo, a vida cultural constituiu-se como um elemento representativo na conformação das dinâmicas sociais do centro tradicional da cidade (Rabêlo, 2013), o que garantiu ao Cine Brasil sua importância histórica.

Porém, a expansão urbana das últimas décadas do século XX, responsável pela migração das classes abastadas para novos bairros, atrelada à falta de atuação do poder público na área central, afetou, tanto a dimensão pública da localidade quanto os equipamentos culturais ali presentes que, devido à falta de público, tornaram-se obsoletos com o passar dos anos. Como consequência desse processo, alguns estigmas foram sendo criados, e o centro passou a ser considerado, para muitas pessoas, um local perigoso e marginalizado, quando o uso popular e a informalidade já predominavam no espaço público.

O processo de decadência do Cine Brasil é concomitante a esse cenário de degradação, culminando daqueles que se fazem presentes na região da Praça Sete, especialmente, o quarteirão onde situa-se o Cine Brasil, uma vez que os outros trechos não sofreram mudanças decorrentes do novo equipamento cultural e as práticas populares estabelecidas há décadas continuam do mesmo modo. Mesmo quando há eventos promovidos pela casa, a movimentação não reverbera em tais locais. A ocupação breve e pontual dos frequentadores ocorre somente no espaço público do entorno imediato do próprio edifício.

As inúmeras tipologias comerciais (lanchonetes, bares, bancos, lojas de roupa) vistas em toda a região da Praça Sete contribuem para a intensa movimentação dos pedestres que transitam diariamente pela localidade, além do acentuado fluxo de veículos e de diversas ocupações sociais presentes na área, comprovando que as intervenções realizadas contribuíram para a manutenção do dinamismo local. O comércio informal também se faz notável e é acompanhado por diversos apelos visuais e sonoros em busca de clientes. A tradição dos jogos de xadrez é mantida em trechos específicos por homens de todas as idades. Policiais são assíduos na região e fazem constantes rondas para demarcar sua presença. Edifícios históricos compõem a paisagem urbana e alguns deles ainda mantêm seus usos originais, como alguns cafés tradicionais, hotéis e o 
próprio Cine Brasil, que segue sendo um importante espaço cultural para a cidade.

Os estigmas negativos em torno do centro, surgidos nas últimas décadas do século $X X$, ainda se fazem presentes no imaginário de muitos cidadãos, como foi evidenciado através das falas e percepções de grande parte dos comerciantes da região. A pobreza ali presente é relacionada por estes à presença de grupos marginalizados na Praça Sete (moradores de rua, usuários de droga, pedintes), que são associados aos pequenos furtos cotidianos e ao perigo e criminalidade que muitos relatam após o fechamento do comércio, à noite, quando a movimentação diminui significativamente.

Nos fins de semana, principalmente ao anoitecer, a ocupação local se dá em função das atividades de lazer de alguns grupos específicos. Apesar de haver menos gente circulando, a permanência no entorno da Praça Sete é mais notável, tanto nos bares da região quanto no espaço público.

No quarteirão onde localiza-se o Cine Brasil, a movimentação se difere com relação aos demais trechos devido à programação da casa, que se concentra à noite e aos finais de semana. Nesse caso, a chegada do público-frequentador se dá minutos antes do início dos eventos e gera uma pequena aglomeração na entrada do edifício, onde algumas pessoas permanecem para consumir algo dos vendedores ambulantes, conversar ou esperar por alguém. Terminado o evento, o público se dispersa com rapidez, de modo geral, e a permanência na rua é ainda menor, não havendo maiores interações com o entorno. A apropriação do espaço público é, desse modo, esporádica, variando conforme a oferta cultural do dia.

Como mostraram os resultados da pesquisa, e assim como nota-se em muitos casos de renovação territorial que têm como princípio estruturante a cultura, há o predomínio de dois grupos atuantes no espaço urbano, os quais possuem diferentes percepções acerca dos desdobramentos advindos da intervenção. Tal fato reverbera tanto nas representações construídas quanto nas formas de apropriação do espaço, o que nos leva a crer que existem elementos distintos que perpassam o imaginário desses grupos e que se relacionam com o resgate simbólico pretendido nesses casos.

De um lado temos (i) os usuários locais, predominantemente das classes populares. As pessoas deste grupo conformam o cotidiano da localidade (transitam ou trabalham na região) e não frequentam o novo equipamento cultural, em sua maioria; tampouco possuem opiniões positivas sobre as intervenções realizadas na área central, incluindo a reabertura do prédio. Já o outro grupo identificado é composto pelos (ii) usuários/frequentadores do Cine Brasil, que constituem as classes médias. Estas, diferentemente do grupo anterior, possuem opiniões mais positivas acerca das renovações do centro e uma visão romântica e nostálgica acerca dos "tempos áureos" do Cine, garantindo percepções otimistas sobre a reinauguração da casa.

Porém, as narrativas positivas deste último grupo são um tanto paradoxais, pois, apesar de identificarem melhorias na região, tais usuários somente frequentam o centro quando há eventos no Cine, ou seja, de forma esporádica e sem interações com o entorno, não havendo apropriação do espaço público renovado por parte desses atores. Suas percepções são, portanto, construídas num dado momento em que eles vivenciam o local, o que parece ser suficiente para se mostrarem felizes com a nova possibilidade de consumo cultural. Um dos entrevistados comenta: "Durante a semana não costumo vir [ao centro] porque tem muita gente, acho confuso, não gosto" (entrevista realizada em 2019). Em contraponto, quando abordados sobre a reinauguração da casa, as impressões são distintas, como demonstra a fala a seguir: "A restauração desse prédio [Cine Brasil] ficou excelente! O espaço interno é maravilhoso e ter um lugar assim, em plena Praça Sete, é muito importante pra cidade!" (entrevista realizada em 2019).

Já os usuários locais possuem uma visão mais negativa sobre o novo espaço cultural, inclusive comentam que o cenário piorou. Muitos associam a sensação de insegurança às intervenções recentes, ressaltando que os novos equipamentos e mobiliário urbano permitem que muitos moradores de rua, considerados atores marginalizados, permaneçam por mais tempo na localidade, o que estaria prejudicando o comércio da região. Isso é revelado na fala de alguns comerciantes e trabalhadores informais: "O centro acabou, é um lixo. Esses quarteirões viraram moradia de mendigo, só tem morador de rua" (entrevista realizada em 2019); "O centro mudou muito, tem muita gente, barulho, roubo. Tudo vende aqui nessa praça, tem de tudo, é muito perigoso" (entrevista realizada em 2019).

Contudo, apesar das novas atrações culturais promovidas pelo Cine Brasil, a existência de um novo público composto pelas camadas médias não promoveu, até então, uma mudança expressiva na composição social local, já que a programação da casa se concentra nos finais de semana e à noite, quando não há muita gente circulando na região. Assim, a frequência esporádica e pontual dos novos atores não reverbera nos usos populares do espaço público cotidiano. Ademais, a sociabilidade entre eles ocorre somente no Cine Brasil, uma vez que as intervenções ocorridas na Praça Sete não promoveram um "efeito cascata", ou seja, o surgimento de novos empreendimentos capazes de suprir as necessidades desse público, o que poderia levar à criação de novos locais de permanência e promover uma maior circulação e/ ou permanência de tal público na região. 
Dessa maneira, podemos dizer que a reinauguração do Cine Brasil não foi capaz de promover uma gentrificação da localidade, o que é sempre um risco eminente nesses casos de intervenção urbana que se utilizam da cultura como estratégia de renovação. Contudo, não é possível afirmar que o novo local tem sido capaz de promover, como era esperado, um espaço de inclusão social ao democratizar o acesso à cultura, já que o público-frequentador segue conformado pelo padrão tradicional dos consumidores de cultura e a região central segue como palco da vida cotidiana dos mesmos grupos.

\section{São Paulo e Recife: Diferentes formas de resistência}

Localizado na área central da cidade de São Paulo, o Bairro da Luz, um dos mais antigos da cidade, é composto por uma série de instituições culturais e edifícios tombados. Sua histórica ocupação popular e de baixa renda no que diz respeito aos usos residencial e do espaço público (informalidade, consumo de drogas, prostituição) levou ao surgimento de diversos estigmas em torno do Bairro, inclusive entre os próprios moradores e frequentadores da região. Conforme aponta Frúgoli Jr. (1995), a presença de grupos marginalizados em determinados territórios pode solidificar representações urbanas negativas, como vem ocorrendo no Bairro da Luz desde as últimas décadas do século XX.

Em 2005, retomando ações iniciadas na década de 1980 para transformar a região da Luz em um "bairro cultural", muitas construções históricas foram reformadas através de parcerias público-privadas para a implementação de novos usos no intuito de atrair pessoas e atividades de maior renda, o que poderia contribuir para reverter o quadro de degradação socioespacial. Além disso, houve uma série de demolições visando a substituição populacional a partir de novas construções para a reconfiguração da "Nova Luz".

No prédio da antiga Estação da Luz (1901), marco inaugural do bairro, inaugurou-se o Museu da Língua Portuguesa ${ }^{8}$. Em seu entorno, outros equipamentos culturais já haviam sido recuperados, como a Pinacoteca do Estado, o Museu de Arte Sacra, entre outros; ou implementados, como a Sala São Paulo (sede da Orquestra Sinfônica do Estado), situada no prédio da Estação Ferroviária Júlio Prestes.

Os discursos do poder público, apoiado pelos meios de comunicação, tendiam à necessidade de combate à degradação socioespacial e à criminalidade decorrentes da "Cracolândia", que diz respeito aos atores marginalizados presentes no bairro, em especial os usuários de crack, os traficantes e as prostitutas. A ideia da "Nova Luz", portanto, girava em torno da eliminação da Cracolândia e, logo, dos estigmas que a envolviam para a criação de uma nova paisagem urbana com a chegada de novos frequentadores, serviços e negócios. Nesse caso, a intenção gentrificadora por trás das propostas tornou-se evidente no próprio discurso do poder público, que visava abolir os grupos considerados marginalizados.

Tal como ocorreu em Belo Horizonte com o Cine Brasil, os equipamentos culturais do Bairro da Luz não são frequentados pelos moradores e/ou comerciantes locais, e a frequência circunstancial de pessoas das camadas médias não afetou os usos já estabelecidos no espaço público referentes às camadas populares. Também não se constataram mudanças relevantes nas atividades comerciais do entorno dos equipamentos ou na vida cotidiana local, pois as atrações culturais concentram-se nos finais de semana, como no caso do Cine, e os novos usuários são estritamente consumidores de tal programação e não permanecem naquele espaço urbano por muito tempo.

Como evidenciado na pesquisa de Frúgoli Jr. e Sklair (2009), as diversas propostas realizadas não foram capazes de eliminar a Cracolândia, cuja permanência foi constatada após a requalificação. Houve apenas um deslocamento da população que a configura para outros espaços públicos do próprio bairro, o que fez com que os estigmas existentes permanecessem no imaginário da população. Portanto, a composição social local não foi alterada apesar das renovações, uma vez que não se desenvolveram novas interações sociais. Nesse caso, a intenção gentrificadora das políticas adotadas não se concretizou (até então), mesmo diante da valorização do patrimônio cultural. As classes abastadas parecem não se sentir atraídas para frequentar ou investir em negócios na região, apontando a resistência dos grupos estigmatizados. A evidente exclusão social diante do espaço público renovado continua latente no Bairro da Luz.

No caso de Recife, capital pernambucana, vamos falar do Bairro do Recife Antigo, marco zero da cidade e antiga zona portuária que possui grande importância histórica e simbólica para a população. Seu processo de revitalização teve início nos anos 1990, quando mais da metade deste território, composto por diversos casarios (antigas moradias dos trabalhadores), armazéns e pontos comerciais, já se encontrava desocupada e bastante deteriorada devido ao processo de decadência iniciado na década anterior com o surgimento do novo porto.

As parcerias entre o poder público e a iniciativa privada se utilizaram do patrimônio local para transformar a referida porção do centro histórico em um local de lazer e consumo cultural, seguindo o denominado marketing urbano, também visto em outras políticas de preservação patrimonial no Brasil (Leite, 2008). O patrimônio é, dessa forma, convertido em mercadoria cultural em prol do 
entretenimento, do consumo e do turismo, sendo capaz de atrair pessoas e capital através da nova paisagem urbana.

A intenção higienista/gentrificadora da proposta tornou-se evidente à medida em que as intervenções se iniciaram no polo Bom Jesus. Os residentes remanescentes dos sobrados foram removidos para a reforma das edificações, nas quais, consequentemente, foram implementados novos usos ligados a gastronomia (bares e restaurantes) e voltados para os jovens de classe média, que logo se apropriaram do local.

Foram observadas distintas formas de ocupação e sociabilidades entre os novos consumidores culturais em comparação aos usuários do cotidiano local, o que exaltou ainda mais as desigualdades sociais. O interessante, neste caso, foi o surgimento espontâneo de um local não previsto no Plano de Revitalização: o polo Moeda. Este se tornou o "ponto de fuga" dos grupos excluídos do enobrecido polo Bom Jesus, cujas demarcações físicas e simbólicas do local contribuíram para a saída destes.

Já o Largo do Marco Zero, que antes era um local de permanência e encontro durante o dia, tornou-se local de passagem após a retirada das árvores e de seu mobiliário urbano. O objetivo era a configuração de um grande palco para eventos e espetáculos públicos noturnos. Mas o clima de festa atribuído ao local o converteu em um espaço sem fronteiras, onde os mais diversos grupos começaram a se reunir, o que não foi visto nos polos Bom Jesus e Moeda, cujos contornos eram facilmente reconhecidos e segregadores.

Ademais, o grande local aberto e sem barreiras promoveu o denominado contra-uso (Leite, 2008), ou seja, o uso previsto para o Largo foi subvertido pelas práticas ali desenvolvidas, que transformaram o lugar no palco principal para a realização de manifestações políticas e sociais da cidade. Houve, portanto, uma reapropriação simbólica deste sítio histórico e, logo, sua ressignificação. A confluência, neste local, das diferentes sociabilidades construídas no bairro evidenciou formas plurais de apropriação do espaço público entre os mais distintos grupos e frequentadores e, desse modo, promoveu a inclusão social diante das representações construídas em torno deste novo espaço urbano.

\section{Representações e ressignificações do espaço público renovado}

O espaço público tem sido alvo de inúmeras discussões na contemporaneidade devido às inúmeras transformações socioespaciais que vêm ocorrendo com a crescente urbanização das cidades e outros fenômenos relacionados. Alguns autores apontam sua crise ou até mesmo sua "morte", enquanto outros defendem seu caráter de resistência como espaço político e da diversidade. Entendido sociologicamente como lugar de encontro e de interações sociais, o espaço público se constitui, dessa maneira, como algo que transcende a rua, possibilitando distintas experiências a partir da pluralidade de intercâmbios que podem ali se materializar. Por serem considerados locais de interações entre estranhos e abertos a todos, os espaços públicos promovem tanto a imprevisibilidade advinda do encontro com o desconhecido quanto o conflito (Andrade \& Baptista, 2015). E ainda, no sentido simmeliano, é importante ressaltar que tais interações se dão a partir de um relativo distanciamento, considerado necessário para garantir a liberdade e a autopreservação do sujeito metropolitano. Esse comportamento, muitas vezes, pode ser confundido com ausência de interação, o que nos levaria em direção à crise do espaço público. Por isso é relevante incorporarmos certa superficialidade no contexto das interações sociais contemporâneas.

Portanto, podemos dizer que o espaço público se conforma por meio das práticas sociais que 0 estruturam, logo, através das ações dos sujeitos. Tais ações dão sentido ao lugar; ou melhor, é no curso destas que o sentido lhe é dado e, assim, o lugar é criado (Leite, 2008). Ele é, portanto, fruto de uma construção social. Os significados a ele atribuídos podem ser múltiplos, variando de acordo com os grupos atuantes e refletindo as dinâmicas urbanas da sociedade, podendo, inclusive, revelar as desigualdades e os conflitos existentes. Assim, compreender as sociabilidades constituintes do espaço público contemporâneo nos permite identificar alguns fenômenos que se apresentam na atualidade, como exemplificado pelos casos de renovação abordados neste trabalho.

É preciso, portanto, olhar para as dinâmicas emergentes, mesmo que seja através das contradições e dos conflitos manifestados pelos diversos tipos de interação presentes na atualidade. Nesse sentido, o espaço público torna-se lugar de resistência e exercício de poder por parte de alguns grupos, já que ele nunca foi, de fato, um espaço democrático, como afirma Hancen (2000, apud Andrade \& Baptista, 2015). Dessa forma, as distâncias sociais que ali se manifestam podem ser retratadas tanto pela ausência de interação de classes quanto pelos usos relativos aos distintos grupos, que variam de acordo com os estratos sociais, como no caso do Cine Brasil.

Nas diversas intervenções realizadas em centros degradados, utilizando-se do patrimônio cultural como principal estratégia de renovação, encontramos cenários de mudanças socioespaciais e econômicas, mas também de muitas permanências. Estas últimas, geralmente, se relacionam aos grupos de menor poder aquisitivo, que não se sentem contemplados pelas revitalizações por não 
terem acesso aos espaços renovados. Dessa forma, a reapropriação do patrimônio cultural se dá apenas para uma parcela da população, as camadas mais abastadas, enquanto os usuários locais permanecem com sua apropriação cotidiana. O resgate do valor simbólico pretendido ocorre, portanto, somente para uma parcela da população que consegue, inclusive, desconstruir as representações majoritariamente negativas em torno do espaço renovado, tal como ocorreu em Belo Horizonte.

\section{Considerações finais}

Este artigo aborda a reinauguração do Cine Brasil como um modelo de revitalização urbana cujo objetivo foi corroborar a renovação de uma área considerada degradada em termos socioeconômicos, no caso, a região da Praça Sete, no centro de Belo Horizonte. O apelo cultural e, portanto, o resgate do valor simbólico do prédio foi a principal estratégia para o alcance das metas desenhadas pelo poder público. Pode-se dizer também que o arranjo feito para viabilizar o novo espaço cultural se assemelha a outros casos nos quais são realizados parcerias ou acordos com a iniciativa privada para a promoção de novas formas de consumo cultural direcionadas, de modo geral, para as camadas mais abastadas da população. Nota-se, assim, um viés neoliberal condutor do processo, que coloca nas mãos do poder privado a gestão de equipamentos culturais. Dessa forma, como apenas parte da população é contemplada com a nova oferta cultural, podem surgir novas formas de apropriação no espaço urbano com a chegada de novos atores.

Acerca dos desdobramentos advindos com a reabertura do Cine Brasil, é possível afirmar que não houve alterações significativas na porção central investigada em termos socioespaciais. A programação cultural do novo espaço, por ser majoritariamente dirigida para as camadas médias da população, não vem sendo capaz de modificar os usos cotidianos já estabelecidos, pois os eventos ofertados ocorrem, principalmente, no período noturno dos finais de semana. Portanto, a presença circunstancial dos novos atores não repercute nas dinâmicas populares presentes no espaço urbano revitalizado, uma vez que tal público não frequenta o dia a dia da região e, quando lá está, não interage com o entorno, sendo mero consumidor cultural do novo equipamento.

Certamente, o desejo de renovar os espaços coletivos da área central e promover uma vida social interclasses possibilitou a preservação do Cine Brasil, cuja reinauguração foi essencial para as renovações almejadas para a Praça Sete. A reforma completa do prédio foi muito importante para a cidade, considerando que o edifício é um dos poucos cinemas de rua sobreviventes. Além disso, o novo uso atribuído ao Cine foi bastante relevante para reaver o centro como um local de lazer e cultura, mesmo que seja apenas para parte da população. Mas percebe-se que existem alguns limites nessas intervenções, que estão relacionados com as representações elaboradas pela população acerca dos espaços revitalizados, e que nem sempre dialogam com os objetivos desejados.

À semelhança do Bairro da Luz, em São Paulo, onde diversas instituições culturais foram reativadas e outras inauguradas, não houve grandes transformações no modo de vida dos que frequentam o cotidiano da região, nem tampouco a substituição de grupos sociais, apesar das alterações estéticas. Em ambos os casos, a ocupação popular que predomina há décadas parece resistir frente às tentativas de construção de uma nova paisagem urbana, por um lado, evitando, a gentrificação, mas, por outro, evidenciando as disputas territoriais entre os excluídos e os usuários do espaço público renovado.

Esse cenário também pode ser visto no Bairro do Recife Antigo, com algumas diferenças. Nesse caso, a resistência das camadas menos favorecidas ocorreu em decorrência de um polo gentrificado que, através das barreiras físicas e simbólicas impostas, fez emergir um movimento espontâneo de alguns grupos sem acesso ao local, seja por vontade própria, seja pela ausência de recursos financeiros e/ ou capital cultural. Com isso, configurou-se um novo lugar, imprevisto, demonstrando a força existente nas práticas sociais locais. Além desse movimento, constatou-se também a transformação do Marco Zero, cujo espaço sem fronteiras, programado para receber grandes eventos noturnos, se converteu num lugar híbrido, para além do consumo e do lazer, onde diferentes grupos começaram a estabelecer suas dinâmicas. O lugar foi, portanto, convertido em palco de manifestações sociais e políticas, lugar de disputas e negociações, cujas representações construídas por cada grupo diferem, sendo, contudo, convergente o sentido atribuído ao lugar.

Diante da reflexão proposta por este trabaIho, faz-se necessário pensarmos em soluções de desenvolvimento urbano para além do consumo cultural e do retorno financeiro, que não se pautem por processos frequentemente de controle social e higienização urbana. Devemos olhar para as resistências que vêm se consolidando nesses territórios revitalizados, para os atores sociais que se reinventam na apropriação do espaço urbano, demonstrando que o direito à cidade é de todos. Caso contrário, ao invés de alcançarmos a cidade diversa, os interesses do capital privado imobiliário continuarão ditando as regras e (re)configurando as desigualdades. 


\section{Notas}

1 Ver Salles (2019).

2 É importante salientar que o termo revitalização, para alguns autores, não é considerado apropriado, pois remete à ideia de recuperar um local desvitalizado (sem vida), o que nem sempre é verdade. De qualquer forma, tal termo é bastante empregado no Brasil para denominar os projetos que visam a recuperação de centros urbanos e será, portanto, adotado neste artigo.

3 Inicialmente, o termo cunhado por Ruth Glass se referia à chegada de novos residentes mais abastados que expulsavam os moradores de baixa renda, causando, além de mudanças físico-espaciais, alterações nas relações sociais locais.

4 As denominadas parcerias público-privadas foram, inclusive, regulamentadas pelo governo federal brasileiro como instrumento de política urbana em 2001, com o Estatuto da Cidade, apesar de já implementadas anteriormente (Cota, 2013)

5 Podemos citar os casos espanhóis do Museu Guggenheim, em Bilbao, ou o Porto Olímpico de Barcelona, dentre outros exemplos de transformações urbanas ocorridas no contexto europeu, como em Lisboa (Portugal), Berlim (Alemanha) e Paris (França) (Solà-Morales \& Costa, 2005).

6 Belo Horizonte foi inaugurada em 1897, portanto, possui pouco mais de 100 anos.

7 A programação do novo espaço cultural é composta por apresentações de música, dança, teatro, exposições, mostras de cinema e eventos diversos (debates, congressos, visitações guiadas).

8 O Museu, inaugurado em 2006, encontra-se fechado desde dezembro de 2015, quando um incêndio de grandes proporções destruiu parcialmente o prédio. Sua reabertura está prevista para julho de 2021.

\section{Referências bibliográficas}

Andrade, L., \& Baptista, L. (2015). Espaços públicos: Interações, apropriações e conflitos. Sociologia: Revista da Faculdade de Letras da Universidade do Porto, XXIX, 129-146.

Bidou-Zachariasen, C. (2006). Introdução. In C. Bidou-Zachariansen, D. Hiernaux-Nicolas \& H. Rivière D'arc (Orgs.), De volta à cidade: Dos processos de gentrificação às políticas de "revitalização" dos centros urbanos (pp. 21-57). Annablume.

Compans, R. (2004). Intervenções de recuperação de zonas urbanas centrais: Experiências nacionais e internacionais. Em A. A. Comin \& N. Somekh (Coords.), Caminhos para o centro: Estratégias de desenvolvimento para a região central de São Paulo (pp. 24-60). Emurb.
Corte-Real, M. (2015, outubro). Revitalizar como e para quem no contexto das intervenções territoriais na cidade interior - 0 estudo de caso da Mouraria. Cahier, 4, 83-99.

Cota, D. (2013). A parceria público-privada na política urbana brasileira recente: Reflexões a partir da análise das operações urbanas em Belo Horizonte. Letra Capital.

Frúgoli Jr., H. (1995). São Paulo: Espaços públicos e interação social. Marco Zero.

Frúgoli Jr., H. (Ed.) (2000). Centralidade em São Paulo. Trajetórias, conflitos e negociações na metrópole. Edusp.

Frúgoli Jr., H., \& Sklair, J. (2009). O Bairro da Luz em São Paulo: Questões antropológicas sobre o fenômeno da gentrification. Cuadernos de antropología social, 30, 119-136.

Jayme, J., \& Trevisan, E. (2012, maio/agosto). Intervenções urbanas, usos e ocupações de espaços na região central de Belo Horizonte. Civitas, 2, 359-377.

Leite, R. (2006). Margens do dissenso: Espaço, poder e enobrecimento urbano. In $\mathrm{H}$. Frúgoli Jr., L. Andrade \& F. Peixoto (Orgs.), A cidade e seus agentes: Práticas e representações (pp. 23-44). PUC Minas/Edusp.

Leite, R. (2008, dezembro). Localizando o espaço público: Gentrification e cultura urbana. Revista Crítica de Ciências Sociais, (83), 35-54.

Lemos, C. (2010). Antigas e novas centralidades: A experiência da cultura do consumo no centro tradicional de Belo Horizonte. Belo Horizonte: Escola de Arquitetura da UFMG.

Moreira, C. (2009). Revitalização urbana e patrimônio cultural: Programa centro vivo. In S. Azevedo \& A. Nabuco (Orgs.). Democracia participativa: A experiência de Belo Horizonte (pp. 119-142). Leitura.

Rabêlo, J. (2013). Belo Horizonte: Do arraial à metrópole - 300 anos de história. Editora Graphar.

Salles, R. (2019). A cultura e o resgate simbólico de áreas centrais: O caso do Cine Brasil e seus efeitos em Belo Horizonte (Dissertação de mestrado). Programa de Pós-Graduação em Ciências Sociais, Pontifícia Universidade Católica de Minas Gerais, Belo Horizonte.

Sant'Anna, M. (2010). Projeto urbano e novas centralidades: Notas sobre o caso de Belo Horizonte. Em Congresso Brasileiro de Organização do Espaço, Rio Claro.

Solà-Morales, I., \& Costa, X. (2005). Metrópolis. Gustavo Gili.

Esta obra está licenciada com uma Licença Creative Commons Atribuição - 4.0 (CC BY 4.0).

Recebido a 11/08/2020. Aceite para publicação a 13/04/2021.

Renata de Leorne Salles. Doutoranda em Ciências Sociais; Pontifícia Universidade Católica de Minas Gerais PUC Minas, Belo Horizonte, Brasil. Email: renatasalles2020@gmail.com 